\title{
Prevalence and Determinants of Tobacco use Among Pre-University College Students, Bangalore, India
}

\author{
Mathews Baby, ${ }^{1}$ Priyadarshini Hesarghatta Ramamurthy, ${ }^{2}$ Darshana Bennadi, ${ }^{3 *}$ Vinayaka Sannafakirappa Konakeri ${ }^{4}$ \\ 'Department of Public Health Dentistry, Assistant Professor, Malabar Dental College and Hospital, Malapuram, Kerala, INDIA. \\ 2Department of Public Health Dentistry, Srinivas Dental College, Mangalore, INDIA. \\ ${ }^{3}$ Department of Public Health Dentistry, Sree Siddhartha Dental College and Hospital, Tumkur, INDIA. \\ ${ }^{4}$ Department of Public Health Dentistry, Malabar Dental College and Hospital, Malapuram, Kerala, INDIA.
}

\begin{abstract}
Aim: To assess the prevalence and determinants of tobacco use among the Pre-University College (PUC) students of Bangalore. Material and Methods: A cross sectional study was carried out among 1450 Government PUC students of Marathahalli, Bangalore. A self administered questionnaire modified from Global Youth Tobacco Survey 2007 (GYTS) was used to collect data. The data was analysed using SPSS version 17. Descriptive statistics that included mean and percentages were calculated for each of the categories. Results: $1443(99.5 \%)$ students had heard about tobacco. $124(8.6 \%)$ students used tobacco in one or other form. Cigarette was the most common form known to the students. About $40 \%$ admitted that they were influenced by their friends to use tobacco. About $1247(86 \%)$ of the students admitted that they were willing to quit tobacco if assistance was provided. Conclusion: Prevalence of tobacco use among Government PU
\end{abstract}

colleges was $8.6 \%$. There is the need for effective awareness and intervention programs to prevent and control tobacco use among college students.

Key words: Prevalence, GYTS, Pre University students, Oral cancer, Tobacco, Smoking.

Correspondence :

Dr. Darshana Bennadi,

Department of Public Health Dentistry, Sree Siddhartha Dental College and

Hospital, Agalkote, Tumkur, INDIA-572107.

Phone no: 9164984840

E-mail: darmadhu@yahoo.com

DOI: 10.5530/jyp.2016.2.11

\section{BACKGROUND}

Oral health is a standard of health of the oral and related tissues which enables an individual to eat, speak and socialize and which contributes to general well being. ${ }^{1}$

Tobacco use is recognised as a major public health problem faced by both developing and developed countries. It has been estimated globally that out of 1.3 billion smokers, $80 \%$ live in developing countries and expecting an increase from 5.4 million deaths per year to more than 8 million deaths a year by the year 2030. It was found that $70 \%$ of the people who die due to smoking belong to low and middle income nations. ${ }^{2}$

Smoking of cigarette particularly beedies and chewing tobacco (smokeless use) is an age-old practice in India. ${ }^{3}$ It is estimated that tobacco use cause 800,000 deaths annually in India. The deaths attributable to tobacco, in India, are expected to rise from $1.4 \%$ of all deaths in 1990 to $13.3 \%$ in $2020 .{ }^{4}$ It is estimated that 5500 adolescents start using tobacco every day in India, joining the 4 million young people under the age of 15 who already are regularly using tobacco. ${ }^{4}$

Karnataka with its share of about $25 \%$ is the second largest tobacco cultivated state mainly Flue Cured Virginia Tobacco (FCV). Mysore (HD Kote, Hunsur, Periyapatna, Ramanathapura) and Shivamoga are the predominant tobacco cultivating districts. ${ }^{5}$

Tobacco use usually begins in adolescents; at the time of their observation, understanding, struggling and facing challenges and psychological development. ${ }^{6}$

Children and teens are easily influenced by the tobacco through their friends, TV, movies, advertisements in different medias. They don't realize what a struggle it can be to quit. And having cancer, emphysema, blindness, or impotence may not seem like real concerns. Children and teens don't think much about future health outcomes. ${ }^{7}$

College life is an important transition period during which young adults begin to explore tobacco use. ${ }^{3}$ Many studies have reported that tobacco smoking is rising in young adult between the ages of 18-24 years as they are legal targets of tobacco industry marketing and increased the prevalence of smoking among college students. ${ }^{3}$

There is an urgent need to curb tobacco use among students. Hence, this study was conducted to estimate the prevalence of tobacco use among the pre university students of the Government colleges in and near Marathahalli and to find the reason for use of tobacco products.

\section{METHODOLOGY}

A descriptive cross sectional study was conducted to assess the prevalence and determinants of tobacco use and to create awareness about hazards of tobacco use among government Pre University College students of Marathahalli, Bangalore city. A list of govt aided and unaided pre university colleges was obtained from the department of pre university education Bangalore (DPUE). All the Govt. Colleges in the marathahalli area were included in the study. Ethical clearance was obtained from institutional ethical committee board. Prior permission was obtained from the Principals of respective colleges to conduct the present study. The colleges which gave permission and students who were present at the time of the study and gave informed consent were included in the study. Study involved 1450 students who were present on that day.

A self administered questionnaire modified from Global Youth Tobacco Survey 2007 (GYTS) ${ }^{5}$ was used to collect data. The questionnaire was prepared in the local language Kannada. The questionnaire was a mix of open-and close-ended questions. The questionnaire consisted of 27 close ended questions pertaining to knowledge, attitude and practices regarding tobacco use adopted from GYTS. Most of the questions in GYTS were pertaining to the recent tobacco use i.e., past one month or thirty days. However in our study, we intended to record a life time exposure to tobacco, hence no time span was included. The questions spanned from whether they had heard about tobacco, different forms of tobacco, source from which they got to know about tobacco, when 
and why did they use tobacco for the first time, who influenced them to use tobacco, frequency of using tobacco products, willingness to quit tobacco, opinion about banning tobacco in public places etc. included in our questionnaire.

Pre Testing of the questionnaire was done in one of the colleges which were not included in the final study, accordingly necessary modifications were done. All the five colleges were visited personally. After explaining the purpose of the survey, instructions were given on how to fill the questionnaire. The voluntary and anonymous nature of participation in the survey was also explained. The questionnaires were distributed among all the $1^{\text {st }}$ and $2^{\text {nd }}$ year pre university students present on the day of the study and requested to complete the questionnaire individually. The collected data was subjected for statistical analysis using SPSS software and analysed Descriptive statistics, Chi-square test for differences between groups. p value 0.05 or less was considered statistically significant.

\section{RESULTS}

The study population consists of 1450 students of $1^{\text {st }}$ and $2^{\text {nd }}$ year pre university colleges. The mean age of students was $16.5 \pm 8$ yrs. Among them $686(47.3 \%)$ were males and $764(52.7 \%)$ females. Majority of students $(99.4 \%)$ had heard about tobacco. (Figure 1) shows study population according to family members using tobacco.

1184 (81.6\%) knew Cigarette was the most known form followed by bidis 896 (62\%), 170 (12\%) students knew about smokeless tobacco and $232(16 \%)$ knew majority types of tobacco. Students $(n=1032,71 \%)$ got tobacco related information and its ill effects through the lectures, awareness programmes within the college itself.

21(1.4\%) students started the tobacco use by getting influence from friends and 268(18\%) students feel that smoking makes them more attractive. Table 1 shows distribution of study population according to reasons for starting smoking. Majority of the students (i.e., 1184 (82\%)) very well knew that tobacco use is harmful to health and $(n=1018$, $70.20 \%)$ knew that passive smoking was injurious to health.

$124(8.6 \%)$ students who were males admitted that they had tried tobacco in the form of smoking cigarettes and chewing form (star, gutaka etc) at least once and 1326(91.4\%) had never tried. Table 2 shows the factors responsible for their tobacco use.

$59 \%(n=73 / 124)$ revealed that they got their tobacco products from a store, shop or from a street vendor (Figure 2). 19\% $(n=23 / 124)$ use tobacco in public places (e.g. parks, shops, street corners) (Figure 3). $38 \%(n=47 / 124)$ students said that they were not able to buy tobacco because of their age while $21 \%(n=26 / 124)$ had no problem in buying tobacco products.

Table 2 and 3 shows distribution of study population according to tobacco use for the first time, number of cigarettes smoked used per day. Out of 124 students, 62 (50\%) answered it won't be difficult to quit, $34(27 \%)$ told it will be difficult to quit, and 28 (23\%) students didn't respond, whereas $107(86.2 \%)$ were willing to stop tobacco use if assistance was provided, 6(5\%) are not ready to quit tobacco use, $10(8.8 \%)$ didn't respond. 1300 (90\%) were favouring and supporting the government policies like banning smoking in public place.

\section{DISCUSSION}

Tobacco is a major public health problem. Unfortunately, tobacco use is on the rise in several developing countries including India. The burden of tobacco associated diseases such as the chronic obstructive pulmonary disease (COPD) in India is as, or even more serious than in several other countries. ${ }^{89}$ The significance of prevalence data on tobacco use in the youth is important both to assess tobacco as a risk factor and to institute control measures for prevention of those diseases.
Table 1: Distribution of study population response on factors responsible for tobacco use

\begin{tabular}{ccccc}
\hline \multirow{2}{*}{$\begin{array}{c}\text { Determinants of } \\
\text { tobacco use }\end{array}$} & \multicolumn{2}{c}{ Male } & \multicolumn{2}{c}{ Female } \\
\cline { 2 - 5 } & $(\mathbf{n}=\mathbf{1 2 4})$ & (Percentage) & $(\mathbf{n}=\mathbf{0})$ & (Percentage) \\
\hline Influence of friends & 50 & 40 & 0 & 0 \\
Personal set back & 19 & 15 & 0 & 0 \\
Family atmosphere & 10 & 08 & 0 & 0 \\
Media & 05 & 04 & 0 & 0 \\
Stress & 06 & 05 & 0 & 0 \\
No response & 34 & 28 & 0 & 0 \\
\hline
\end{tabular}

Table 2: Distribution of study population according to the age for starting tobacco use

\begin{tabular}{ccccc}
\hline \multirow{2}{*}{$\begin{array}{c}\text { Age for starting } \\
\text { tobacco use }\end{array}$} & \multicolumn{2}{c}{ Male } & \multicolumn{2}{c}{ Female } \\
\cline { 2 - 5 } & $(\mathrm{n}=124)$ & (Percentage) & $(\mathrm{n}=\mathbf{0})$ & (Percentage) \\
\hline 7yrs & 30 & 24 & 0 & 0 \\
$8-9 \mathrm{yrs}$ & 12 & 09 & 0 & 0 \\
$14-15 \mathrm{yr}$ & 32 & 26 & 0 & 0 \\
$\geq 16 \mathrm{yrs}$ & 49 & 40 & 0 & 0 \\
\hline
\end{tabular}

Table 3: Distribution of study population according to tobacco use per day

\begin{tabular}{ccccc}
\hline \multirow{2}{*}{ Tobacco Use } & \multicolumn{2}{c}{ Male } & \multicolumn{2}{c}{ Female } \\
\cline { 2 - 5 } & $(\mathbf{n}=\mathbf{1 2 4})$ & (Percentage) & $(\mathbf{n}=\mathbf{0})$ & (Percentage) \\
\hline Less than 1/day & 19 & 15 & 0 & 0 \\
One/day & 24 & 19 & 0 & 0 \\
2-5/day & 23 & 18 & 0 & 0 \\
6-10/day & 13 & 10 & 0 & 0 \\
More than 20/day & 05 & 04 & 0 & 0 \\
No response & 40 & 33 & 0 & 0 \\
\hline
\end{tabular}

The present study assessed prevalence and determinants of tobacco use among government Pre-University colleges in Marathahalli, Bangalore. This study showed that students were aware of the dangers of tobacco use which is consistent with the study done by Jindal et al. ${ }^{8}$

Present study shows a prevalence of $8.6 \%$ for tobacco use. Smoking appeared to be the predominant form of tobacco use. Among tobacco users all were smokers in which; $96.7 \%$ were cigarette smokers and 3.3\% use beedi and no one reported smokeless tobacco use.

The prevalence of current tobacco use is slightly more than state-level estimates for boys in Karnataka (8\%) and less than the regional estimates for southern India (9.2\%), as reported by the GYTS. ${ }^{5}$ The prevalence of current tobacco use in this study was lower than the national estimate of $17.2 \%$ reported by the GYTS for boys. ${ }^{10,11}$ Similarly, the study from Chennai reported a higher use of tobacco $(41.6 \%$ ever users and $46.3 \%$ current users) among boys than our study. ${ }^{12}$

When comparing the findings from Bangalore with those from north Indian cities, the prevalence of current tobacco use was found to be much lower than that reported by the GYTS ${ }^{11}$ for boys in Ahmadabad but higher to those reported from Mumbai, Delhi ${ }^{13}$ whereas Jaipur ${ }^{14}$ was the only city in north India for which a lower prevalence $(2.1 \%)$ of current tobacco use was found.

A possible discrepancy in results compared with that of other studies could be because of the improved implementation of tobacco-related laws on access to tobacco products by minors, which could account for 


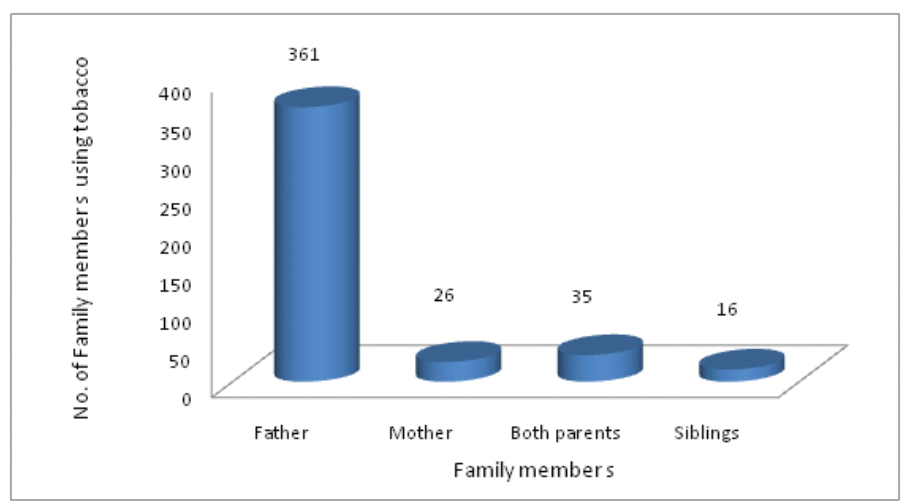

Figure 1: Distribution of study population according to family members using tobacco

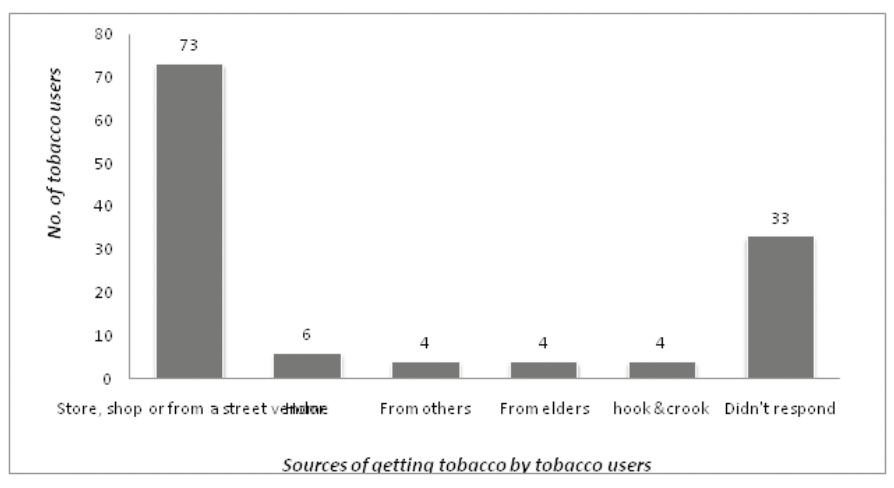

Figure 2: Distribution of Study Population (Tobacco users) according to their sources of Tobacco

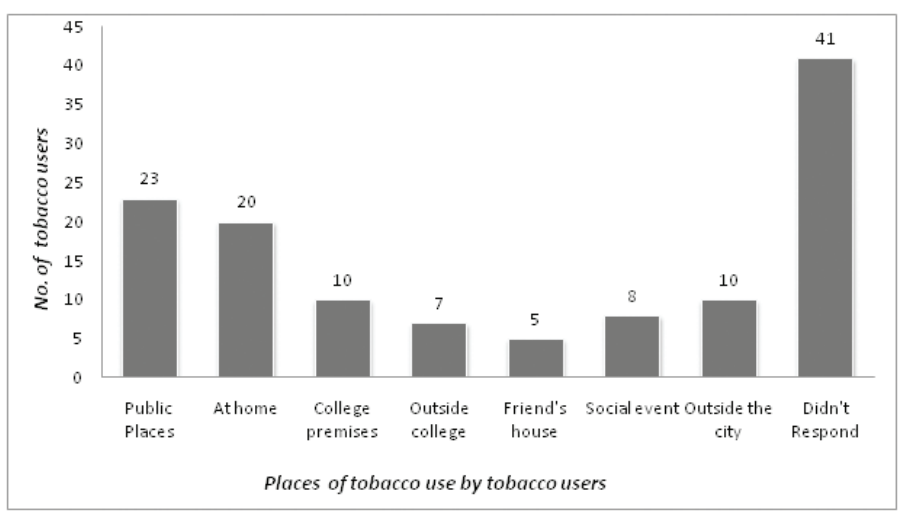

Figure 3: Distribution of Study Population (Tobacco Users) According to Place of Tobacco Use

the relatively low prevalence of tobacco use in current study. With regard to the tobacco consumption pattern (notwithstanding the GYTS for Ahmadabad and the study of children in Karnataka that found a higher prevalence of smokeless tobacco use compared with smoking [the proportions being $8.6 \%$ and $6.3 \%$, respectively], ${ }^{11}$ studies from Chennai, ${ }^{12}$ Delhi $^{13}$ and Jaipur ${ }^{14}$ corroborated present finding of a higher prevalence of smoking compared with smokeless tobacco use. The observations of study $\mathrm{y}^{15}$ on college students in urban areas of Karnataka also confirmed a higher use of smoking (46\%) compared with smokeless tobacco (29.7\%). Moreover, they found that school culture might be an important factor in influencing the pattern of tobacco use, with students from professional educational institutes (i.e. medicine, law and engineering) being more likely to smoke cigarettes compared with students from government, Kannada medium schools who were more likely to use smokeless tobacco products and vice versa. The GYTS sampling technique allows a mix of government and private schools and uses a younger sample than that used in current study. These factors can explain, in part, the variations in the pattern of tobacco use found by the GYTS and current study. Age at onset of smoking in our study was consistent with that observed in developed countries. The studies conducted among U.S. youths for 'smoking by race and ethnicity' and in Jerusalem school children also found the mean age at initiation to be around $12 \mathrm{yr}^{16,17} \mathrm{~A}$ little higher age of initiation was found among Chinese Americans (boys: 12.8, girls: $13.1 \mathrm{yr}$ ), Non-Hispanic white minors (boys: 12.5, girls: $13.0 \mathrm{yr}$ ) and South African students (males: 15.16 and females: $14.98 \mathrm{yr}) .^{18} \mathrm{Among}$ the Indian studies, the mean age of initiation of tobacco use has been found to vary from 8 to $15 \mathrm{yr}^{19}$ Majority of the tobacco users worldwide have reportedly first tried tobacco prior to age 18 , some starting as young as $10 \mathrm{yr}^{20}$ Present survey reflects a recent downward shift in age at uptake of tobacco habit among children. In a study from Kerala the mean age at initiation was $10.7 \mathrm{yr}$ for boys. ${ }^{21}$

This study showed that influence from friends was the most common factor in initiating tobacco use, which is similar to observations from studies in Delhi (38\%) and Mumbai (46\%). ${ }^{11,13}$ Also, tobacco users in present study said that 'friends' were the most common reason for starting tobacco use.

Our study findings are in agreement with, a study from the urban areas of Dakshina Kannada district of Karnataka found that encouragement from friends (40\%), and appearing 'in style' (18\%) were reasons given frequently to start smoking. ${ }^{10,11}$ Similarly, a study from Delhi reported 'enjoyment' and 'curiosity' as major factors that influence adolescents to start using tobacco. ${ }^{13}$ Most (82\%) of the students in this study were aware of the harmful effects of tobacco use; other studies in urban India have reported comparable or higher levels of such awareness. The GYTS for Karnataka reported that $78.7 \%$ and $82 \%$ of boys were aware of the harmful effects of smoking and smokeless tobacco use, respectively. ${ }^{5,11}$ Studies from Delhi ${ }^{13}$ and Jaipur ${ }^{14}$ and have shown that $99.2 \%$ and $80 \%$ of students respectively were aware of the harmful effects of tobacco use on health. This study has amply demonstrated that it is the harmful effects of tobacco use that is the commonest reason for never users to stopped usage of tobacco. Appropriate interventions are needed to reduce tobacco use among students in India. Such interventions should raise awareness of the social and economic implications of tobacco use and equip students to overcome peer influence, while at the same time providing help to quit tobacco use.

One of the limitations of the GYTS is the time taken to answer the questions as it was very lengthy, since we used self administered questionnaire instead of interview, we selected few questions and modified it as per comprehension abilities of the students.

\section{CONCLUSION}

Tobacco use is a leading cause of preventable deaths world over, more so in developing countries. The tobacco situation in India is unique because of a vast spectrum of tobacco products available for smoking as well as smokeless use. The exposure of the habit of tobacco use in adolescence was influenced by various factors like peer pressure, friends, elders, family atmosphere feel great and powerful when smoking and for fun. This study shows prevalence of tobacco smoking in boys only.

There is need for targeted and focused interventions by adopting a comprehensive approach. Anti-tobacco programmes should make inroads into transitional towns and rural areas. The focus in schools should be to make them tobacco-free. The school authorities should 
be included in stricter implementation and monitoring of the implementation of legislation. Regular and systematic education programmes catering to teachers, children and also their parents should be undertaken. Enabling teachers to educate the young impressionable minds regarding life style disorders should be a cornerstone activity in preventing the establishment of life style disorders like tobacco and alcohol use within the community.

\section{ACKNOWLEDGEMENT}

Participants of the study.

\section{CONFLICT OF INTEREST}

The author declare no conflict of interest.

\section{ABBREVIATIONS USED}

GYTS: Global Youth Tobacco Survey.

\section{ABOUT AUTHOR}

Mathews Baby: Department of Public Health Dentistry, Assistant Professor, Malabar Dental College and Hospital, Malapuram, Kerala. Area of interest: Ethics and epidemmiology.

\section{REFERENCES}

1. Adeyeye OO. Cigarette smoking habits among senior secondary school students in lagos, south west Nigeria. Int J Biol Med Res. 2011;2(4):1047-50.

2. Umesh RA, Keshab D. Prevalence and Determinants of Cigarette Smoking among the College Students of Kathmandu Valley. Asian Journal of Medical Sciences. 2010;1(2):53-8.

3. Raj N, Sarita S, Sanjay G. Age at initiation \& prevalence of tobacco use among school children in Noida, India: A cross-sectional questionnaire based survey. Indian J Med Res. 2011;133(3):300-07.

4. Ranabir $P$, Dechenla T. Tobacco use in Indian high-school students. IJGP 2009;3(4):319-23

5. Global youth tobacco survey in Karnataka. Final project report of Global Youth Tobacco Survey-Karnataka, India (Allotment No: SE ICP TOB 002 XK 02). Accessed from; http://www.searo.who.int/linkFiles/GYTS_Rep_Karnataka.pdf Accessed on: 12/09/2011.

6. Surekha K, Garg BS, Khursheed M. Tobacco Addiction Amongst Adolescents in Rural Areas of District Wardha. JK Science. 2007;9(2):79-82.

7. Child and Teen Tobacco Use. American cancer society. Accessed from; www. cancer.org >child and teen tobacco use Accessed on: 12/09/2011

8. Jindal SK, Aggarwal AN, Gupta D, Kashyap S, Chaudhary D. Prevalence of Tobacco Use Among School Going Youth in North Indian States. Indian J Chest Dis Allied Sci. 2005;47(3):161-6.

9. Hindu K, Vanitha RN, Hari PB, Kannan G, Thennarasu P. Impact of Severity of the Disease on Cost of Illness and Quality of Life of Patients with Chronic Obstructive Pulmonary Disease. JYP. 2015;7(2):106-12.

10. Bhojani UM, Chander SJ, Devadasan N. Tobacco use and related factors among pre-university students in a college in Bangalore, India. The National Medical Journal of India. 2009;22(6):294-7.

11. Global youth tobacco survey in India. Final project report of Global Youth
Tobacco Survey-India. Accessed from; www.mohfw.nic.in Accessed on: $12 / 09 / 2011$

12. Madan KPD, Poorni S, Ramachandran S. Tobacco use among school children in Chennai city, India. Indian J cancer. 2006;43(3):127-31.

13. Singh V, Pal HR, Mehta M, Kapil U. Tobacco consumption and awareness of their health hazards amongst lower income group school children in National Capital Territory of Delhi. Indian Pediatr. 2007;44(4):293-5.

14. Singh V, Gupta R. Prevalence of tobacco use and awareness of risks among school children in Jaipur. J Assoc Physicians India. 2006:54:609-12.

15. Nichter M, Nichter M, Van SD. Popular perceptions of tobacco products and patterns of use among male college students in India. Soc Sci Med. 2004:59(2):415-31.

16. Caraballo RS, Yee SL, Gfroerer JC, Ralph S, Pechacek TF, Henson R. Tobacco use among racial and ethnic population subgroups of adolescents in the United States. Prev Chronic Dis. 2006;3(2):A39.

17. Meijer B, Branski D, Knol K, Kerem E. Cigarette smoking habits among school children. Chest. 1996;110(4):921-6.

18. Swart D, Reddy P, Ruiter RA, de Vries H. Cigarette use among male and female grade 8-10 students of different ethnicity in South African schools. Tob Control 2003;12(1):e1

19. Reddy KS, Arora M. Tobacco use among children in India: A burgeoning epidemic. Indian Pediatr. 2005;42:757-61.

20. Ahmed NU, Ahmed NS, Semenya KA, Elzey JD, Larson C, Bennett CR. Prevalence and correlates of initiation of smoking behavior among preteen black and white children. J Natl Med Assoc. 2004;96(2):200-8.

21. Pradeepkumar AS, Mohan S, Gopalakrishnan P, Sarma PS, Thankappan KR Nichter M. Tobacco use in Kerala: findings from three recent studies. Natl Med J India. 2005;18(3):148-53. 